\title{
El sueño premonitorio de Moisés Almosnino sobre Yosef Nasí en el Tratado de los sueños (Salónica 1564)
}

\author{
Pilar ROMEU FERRÉ* \\ «Un sueño no interpretado \\ es como una carta no leída» \\ TB Berajot 55a
}

El sueño premonitorio de Moisés Almosnino sobre Yosef Nasí fue escrito hacia fines de 1563 y publicado en Salónica en 1564 en las hojas finales del Tratado de los sueños. El sueño es utilizado por el autor como recurso literario para augurar a la familia Nasí un venturoso futuro y agradecerle sus incontables atenciones.

\section{MoisÉs Almosnino y Yosef NAsí}

Una de las pocas coincidencias entre ambos personajes, tal vez la más significativa, es que ambos eran judíos sefardíes. Coetáneos en un espacio geográfico y temporal común, sus rasgos distintivos contribuyen a unirlos en el empeño de favorecer a su pueblo en la diáspora.

*tirocinio@tirocinio.com

Sefarad 64 (2004) págs. 159-193

(c) CSIC

ISSN 037-0894 
Moisés Almosnino es un autor de reconocido prestigio ${ }^{1}$. La novelesca historia de Yosef Nasí, también conocido por su nombre cristiano de Juan Míquez o Micas, es célebre y conocida por los estudiosos de la historia judía y no judía ${ }^{2}$.

Moisés Almosnino nació en Salónica en 1518. Su familia, de cierta posición social, provenía de España, de Jaca (Huesca) ${ }^{3}$. La desgracia se cebó en ella, ya que sus abuelos, Abraham Almosnino e Isaac Cogumbriel, perecieron en las hogueras de la Inquisición ${ }^{4}$. Sus padres debieron de nacer en la Península, pero desconocemos el itinerario que siguieron hasta llegar a Salónica.

Yosef Nasí nació en Lisboa unos años después ${ }^{5}$ y era hijo de Samuel Nasí, hermano de la Señora doña Gracia, conocida también por su nombre cristiano de Beatriz de Luna ${ }^{6}$. No sabemos quién era su madre ni cuándo se establecieron en Lisboa. Don Samuel era

1 Existen numerosos estudios acerca de su vida y su obra que recogí en Moisés Almosnino: Crónica de los Reyes Otomanos (Barcelona 1998).

2 Aunque existe un trabajo reciente a propósito del hallazgo de nueva documentación (H. P. SALOMON y A. di L. LeONI, «Mendes, Benveniste, De Luna, Micas, Nasci: The State of the Art (1532-1558)», JQR 88/3-4 [1998] págs. 135212), me atengo también a las obras monográficas de C. RoTH, The House of Nasi: The Duke of Naxos (New York 1948), y P. Grunebaum-Ballin, Joseph Naci, duc de Naxos (París 1968), y, con ciertas reservas, dada la cantidad de imprecisiones biográficas que contiene, a la de J. REZNIK, Le duc Joseph de Naxos: Contribution à l'Histoire Juive du XVIe siècle (París 1936). Todas ellas ofrecen datos contradictorios entre sí, aun en una misma obra. Lo mismo ocurre con los datos que aporta A. Galante, Don Joseph Nassi, Duc de Naxos, d'après de nouveaux documents (Constantinopla 1913).

3 Ahí se documentan muchos Almosnin entre 1479 y 1492 (Cf. M. A. Motis DOLADER, La aljama judía de Jaca en el siglo XV [Huesca 1998] págs. 66-73), pero los Almosnino -Almoxnino o Almuxnino- se encontraban en muchos lugares de Aragón, como vemos en el reciente estudio de F. A. LASCORZ ARCAS, La aljama judía de Monzón, "La Recordada» (Zaragoza 2003) pág. 203.

4 F. BAER, Die Juden im Christlichen Spanien, II (Berlín 1936) págs. 484-509, y Y. BAER, Historia de los judios en la España cristiana (Madrid 1981) pág. 611.

5 Según C. Roth, Duke of Naxos, pág. 3, nació en 1520, y según P. GRUNEBAUM-BALlin, Joseph Naci, pág. 37, nota 2, en 1524 .

6 Acaba de publicarse un estudio que enfatiza su condición de mujer-líder en las cortes europeas y en el Imperio Otomano. Cf. A. AELION BROOKS, The Woman who Defied Kings (St. Paul, MN 2002). 
médico y en 1510 enseñaba «filosofía moral» en la Universidad de Lisboa. Murió hacia $1525^{7}$.

La vida familiar de Almosnino debió de ser muy tranquila. Era el segundo hijo de Baruj Almosnino, dirigente de la comunidad catalana de Salónica hasta su muerte en 1563. Baruj se ocupó de dar a su hijo una educación esmerada y acorde con su rango. Moisés se casó con doña Simhá y de ella tuvo por lo menos dos hijos, Simeón e Isaac, y una hija que vivía en Edirne. Almosnino dejó constancia escrita en sus obras de que viajó varias veces a Constantinopla y a otros lugares del Imperio otomano, pero presumiblemente no fue mucho más allá.

En cambio, Yosef Nasí quedó huérfano muy joven. Su tía doña Gracia, que se había casado con el comerciante Francisco Mendes ${ }^{8}$ en Lisboa en 1528, pasó a hacerse cargo de él y de su hermano mayor, Samuel ${ }^{9}$. Del matrimonio entre Gracia y Francisco, que duró poco porque él murió en 1535, nació una única hija, Reina, que con el tiempo habría de convertirse en esposa de Yosef y duquesa de Naxos. Tras la muerte de Francisco, la familia Mendes -Gracia, su hija Reina, su hermana Brianda y sus sobrinos Yosef y Samuel- se trasladó a Amberes, donde vivía Diego Mendes, hermano del finado, controlando en la plaza los negocios. Diego Mendes y Brianda de Luna, hermana menor de Gracia, se casaron en 1537, y al cabo de otro nació su única hija, Beatriz, llamada la chica, que con el tiempo se casaría con Samuel Nasí, hermano de Yosef. Cuando en 1542 murió Diego Mendes, Gracia tomó las riendas de los negocios familiares ayudada por Yosef, pero las vicisitudes políticas del momento les obligaron a trasladarse primero a Venecia y

\footnotetext{
7 C. Roth, The House of Nasi: Doña Gracia (Philadelphia 1947) pág. 12, y Duke of Naxos, pág. 3.

8 Francisco Mendes era el nombre cristiano de Semah Benveniste (Cf. C. Roth, Doña Gracia, pág. 10), probablemente nieto (o, en todo caso, bisnieto) de Abraham Benveniste, Rabino mayor de la Corte de Castilla, perteneciente a una de las más acaudaladas familias judías. En este sentido, el matrimonio de Gracia reportó grandes beneficios a los Nasí.

9 Aunque C. Roth, Duke of Naxos, pág. 3, dice que era póstumo, por lo que sería menor, y no mayor.
} 
de ahí a Ferrara ${ }^{10}$, hasta poder recalar definitivamente en Constantinopla, hacia $1553^{11}$.

Las ocupaciones de ambos personajes fueron igualmente distintas. Rabino de profesión y escritor vocacional, Almosnino ejerció de modo regular en la comunidad Livyat hen de Salónica hasta su muerte en 1580. Esta comunidad fue creada y financiada por la familia Nasí ${ }^{12}$, y de ahí la estrecha relación entre ambos. Pero además de ocuparse en los quehaceres propios de su cargo, participó muy directamente en los avatares de la comunidad judía de Salónica ${ }^{13}$ y se implicó especialmente en la asistencia espiritual de los nuevos inmigrados judíos, conversos o judíos nuevos ${ }^{14}$. Los judíos no formaban un grupo homogéneo y su situación planteaba numerosos problemas prácticos, jurídicos y religiosos ${ }^{15}$. Muchos conversos retornaron al judaísmo en la diáspora, pero carecían de una sólida

10 Ferrara conoció su esplendor cultural en las décadas centrales del siglo XVI. Sirvió de refugio a judíos y conversos que provenían principalmente de Portugal -como consecuencia del establecimiento allí de la Inquisición en 1536-, del reino de Nápoles -donde se decretó su expulsión en 1541-, e incluso de la propia Península, huyendo de los rigores inquisitoriales. Importantes familias recalaron ahí. Véase R. SEgRE, «Sephardic Refugees in Ferrara: Two Notable Families», en Crisis and Cretivity in the Sephardic World 1391-1648, ed. B. GAMPEL (New York 1997) págs. 164-185.

11 H. P. SAlomon y A. di L. LeOni incluyen un árbol genealógico de esta complicada familia en las últimas hojas de su artículo «Mendes, Benveniste, De Luna, Micas, Nasci...».

${ }_{12}$ Digo Nasí, pues de Yosef, y especialmente de Gracia, partió la idea. Pero no hay que olvidar que la gran fortuna de la que disponían provenía en su mayor parte de la familia Mendes (Benveniste).

${ }^{13}$ Por ello en 1566 encabezó una embajada a la capital para negociar en la Corte los impuestos que gravaban las arcas de los judíos salonicenses y cuyas vivencias dejó plasmadas en la Crónica de los Reyes Otomanos (véase nota 1).

${ }^{14}$ El judío nuevo es un descendiente de cripto-judíos o conversos, socializado en un medio cristiano, y cuyas raíces judías no le fueron transmitidas de padres a hijos. Cf. Y. KaPlan, Judíos nuevos en Amsterdam (Barcelona 1996) págs. 23-28.

15 Véase B. NETANYAHU, Los Marranos españoles según las fuentes hebreas de la época (siglos XIV-XVI) ( $2^{\mathrm{a}}$ ed. Valladolid 2002), y R. LEVINE, «Hommes et femmes: leur role respectif dans la perpétuation de l'identité juive au sein de la société conversa», en Mémoires juives d'Espagne et Portugal, ed. E. BENBASSA (París 1996) págs. 39-50. 
formación judía. Almosnino se hizo eco en sus obras de la falta de formación de estos judíos nuevos.

Por su parte, Nasí fue un hombre esencialmente político. Probablemente era una de esas personas para las que todos los medios son buenos con el fin de conseguir lo que se proponen. Desde que murió Diego Mendes, no dejó de colaborar con su tía sirviéndole de mediador. Gracias a las múltiples sucursales de sus negocios, tenían contactos en muchas ciudades importantes, y ello les sirvió para poder ayudar a los judíos o conversos obligados a desplazarse.

Pero el mayor mérito de Nasí estriba en la ambigüedad de su condición. Era un judío bautizado y, socialmente, cristiano cumplidor. Este disfraz le permitía intrigar en los diversos países con los que tenía trato o a los que sirvió de intermediario. Con los turcos jugaba la carta de ser europeo; para los estados cristianos, era el comodín de la baraja ante la amenaza otomana, judío unas veces, cristiano otras. Uno de sus mayores logros fue su estrecha amistad con el heredero del trono otomano, Selim. Esta favorable posición le permitió trazar una red de intrincados negocios con países vecinos y concebir planes muy ambiciosos para sus aspiraciones políticas. Numerosos documentos de la época prueban que supo aprovecharse de ella para obtener pingües beneficios ${ }^{16}$. Murió en 1579 ostentando el título de duque de Naxos.

Desde el punto de vista literario, la producción de Almosnino no puede compararse a la de Nasí. No voy a detenerme a exponer la obra hebraica de Almosnino, bien conocida en medios rabínicos por

16 Véase A. ARCE, «Espionaje y última aventura de José Nasí (1569-1574)», Sefarad 13 (1953) págs. 276-286; M. BERSOHN, «Einige Worte Don Joseph Nasi, Herzog von Naxos, betreffend», MGWJ 18 (1869) págs. 422-424; A. GALANTE, «Nouveaux documents sur Joseph Nassi, duc de Naxos», REJ 64 (1912) págs. 239 243; D. KAUFMAN, «Don Joseph Nassi, founder of colonies in the Holy Land, and the community of Cori in the Campagna», JQR 2 (1889-90) págs. 291-297; ID., «A letter from the community of Pesaro to don Joseph Nassi», JQR 4 (1891-92) págs. 509-512; ID., «Die Vertreibung der Marranen aus Venedig im Jahre 1550», JQR 13 (1900-01) págs. 525-532; S. RAHN, «Oesterreichisch - Ungarische Gesandtschaftberichte über Don Joseph Nassi», MGWJ 28 (1879) págs. 113-121; y J. REZNIK, Le duc Joseph de Naxos, págs. 231 y ss. 
sus comentarios bíblicos y misnaicos, responsas, piyutim, discursos y sermones. Me limitaré a dar cuenta de sus cinco obras aljamiadas conocidas, escritas entre los años 1560 y 1570.

La primera, el Tratado del Estrolabio ${ }^{17}$, fue escrita en 1560. Cuatro años más tarde, en 1564, se publicó en Salónica el Séfer hanhagat hahayim, más conocida por Regimiento de la vida. Formando cuerpo con ella y a renglón seguido se publicó el Tratado de los sueños ${ }^{18}$. Estas dos obras conocieron al cabo de dos siglos en Amsterdam una segunda edición en caracteres latinos ${ }^{19}$. La cuarta, redactada entre los años 1566 y 1567, fue la Crónica de los Reyes Otomanos, cuya edición parcial y refundida ${ }^{20}$ publicó Iacob Cansino en Madrid en 1638 con el título de Extremos y Grandezas de Constantinopla. Y, en fin, en 1570 escribió el Canon de reloj de plata ${ }^{21}$.

17 Se conserva una única copia manuscrita de 44 págs. en la Biblioteca Saltycov-Schedrín de San Petersburgo. A. MARCOva publicó la transcripción de las siete primeras páginas con un breve estudio en «El Tratado del Astrolabio de Mošé Almosnino en un manuscrito de Leningrado», Sefarad 51 (1991) págs. 437-446. Actualmente, H. SHEYNIN (Gratz College, Philadelphia) ha completado la transcripción del manuscrito y está pendiente de publicación.

${ }^{18}$ La edición global tiene 162 hojas. Las primeras 138 corresponden al Regimiento y a partir de la 139 al Tratado.

${ }_{19}$ El Regimiento en 1729 y el Tratado, con el título de Transformaciones de Morpheo ó Tractado de sueños, en 1734.

${ }^{20}$ Las ediciones en caracteres latinos de las obras aljamiadas de Almosnino reelaboran las antiguas en gran medida. Véase P. ROMEU, «Diferencias y paralelismos entre la Crónica de los Reyes Otomanos de rabí Mošé ben Baruj Almosnino y los Extremos y Grandezas de Constantinopla de Iacob Cansino», en History and Creativity. Proceedings of Misgav Yerushalayim's Third Interrnational Congress, 1988 (Jerusalén 1994) págs. 189-200. Actualmente disponemos de una edición crítica moderna de la Crónica (véase nota 1).

${ }^{21}$ Una breve composición de cuatro páginas manuscritas que se conserva formando cuerpo con el mencionado Tratado del Estrolabio. Algunas de estas obras las recogen A. PALAU, Manual del librero hispano-americano, 28 vols. ( $2^{\mathrm{a}}$ ed. Barcelona 1977), y Y. VinOGRAD, Thesaurus of the Hebrew Book, 2 vols. (Jerusalén 1995), que sigue el criterio de ordenación por lugar de impresión, y para cada uno según la fecha de edición: El Regimiento (A. PALAU, Manual del librero hispano-americano, 8207; Y. VINOGRAD, Thesaurus of the Hebrew Book, Amsterdam 1345), el Tratado (Y. VINOGRAD, Thesaurus of the Hebrew Book, Amsterdam 1434), y los Extremos (A. PALAU, Manual del librero hispanoamericano, 8205). 
El mayor mérito y también el mayor interés que ofrece el conjunto de la obra aljamiada de Almosnino es la de ser en su totalidad de libre creación y redactada originalmente en romance o romance castellano, como él mismo la llama, y que hoy denominamos prejudeoespañol. Fue, sin duda, el más fecundo de los autores sefardíes del siglo XVI.

Frente a esta prolífica producción literaria, a Yosef Nasí se le conoce una única obra ${ }^{22}$, titulada Ben porat Yosef ${ }^{23}$, que fue publicada en Constantinopla en $1577^{24}$, y que consiste fundamentalmente en un alegato contra la astrología. Esta obra fue escrita a raíz de una discusión con un sabio cristiano en un intento por demostrar la superioridad de la religión judía sobre la cristiana. Fue redactada originalmente en portugués y traducida al hebreo por su protegido, el rabino Isaac Onqueneira.

\section{El TRATADO DE LOS SUEÑOS}

El Tratado de los sueños se publicó en el mes de elul de 5324/1564 en Salónica, en la imprenta de Yosef Ya'abes, correlativo con el Regimiento de la vida (19,8 x 15). El texto está entre las hojas $139 \mathrm{r}$ a $162 v$. Tiene entre 39 y 40 líneas por página en una caja de $14,5 \times 8,5$. Cerca de $2 \mathrm{~cm}$ de margen ocupan en cada página, a derecha o izquierda respectivamente, las anotaciones marginales del texto. El asunto principal de la obra es el análisis de los sueños.

El sueño es una función vital para el necesario equilibrio del ser humano, tanto como el comer o el dormir. Es esencialmente un estado de reposo durante el que el individuo desconecta del medio am-

\footnotetext{
22 J. REZNIK, Le duc Joseph de Naxos, pág. 221, habla de un manuscrito de una obra titulada Torat Yosef, pero no lo localiza.

23 Tal vez la elección de este título tenga alguna relación con el hecho de que Ben porat Yosef ('rama -de árbol fértil- es José') es parte de una fórmula talmúdica contra el mal de ojo o los hechizos, con la que se asocia al patriarca José, y que casualmente está en la parte del Talmud donde se trata de los sueños (TB Berajot 55b).

${ }^{24}$ Cf. Y. Vinograd, Thesaurus of the Hebrew Book, Constantinopla 263.
} 
biente. Durante ese periodo, se producen vivencias irreales que son percibidas de muy diversas maneras por el individuo y sobre las que los especialistas están muy lejos de pronunciarse unánimemente, salvo en un punto: el sueño escapa a la voluntad del sujeto.

El significado de los sueños es uno de los capítulos más interesantes, valiosos y gratificantes de la tarea analítica. Descifrar el sueño consiste en descubrir el sentido oculto del mismo a partir de las imágenes que en él se producen, destejiendo la maraña de fantasías para darles un significado. La interpretación psicoanalítica hace consciente lo inconsciente.

Pese al interés que en todas las culturas ha despertado este tema, la producción literaria al respecto es parca y son muy raras las obras monográficas dedicadas al tema, también en la literatura judía. El Tratado de los sueños es la única aljamiada conocida de la época.

El mundo antiguo daba a los sueños un eminente valor premonitorio. La oniromancia o adivinación por los sueños fue una práctica común en todas las culturas. En la Biblia, los sueños no eran más que revelaciones divinas y encajan con el prototipo de sueño profético. En el Talmud no se forjó una teoría unánime; unos tenían en cuenta la personalidad del soñante y sus propias vivencias, pero no faltaron quienes consideraban, como Haniná ben Yishac, que el sueño es una variedad de profecía (Mid. GnR 17:5). En esa época se daba gran importancia a las visiones nocturnas, y así recuerda Almosnino: «Cuentan en nuesso Talmud que por grande cossa dizen que avía en Yeruxaláyim vente y cuatro soltadores de sueños» (146r aludiendo a TB Ber 55b). Bar Hadiá fue uno de los más famosos, aunque es sabido que sus interpretaciones dependían, muchas veces, de algo tan banal como el dinero: a quienes pagaban, interpretaba favorablemente; a quienes no, desfavorablemente.

Durante la Edad Media interesó especialmente a los cabalistas, quienes distinguían entre los sueños del hombre justo y del hombre malvado, planteado ya en el Talmud (TB Ber 55b). Durante toda esta época se produjo un arduo debate acerca de la intervención divina en la interpretación de los sueños, que los más religiosos se oponían a desligar del concepto de profecía. 
En el siglo XIII, Maimónides vino a romper con las tradiciones más arraigadas y adaptó las teorías aristotélicas a la filosofía judía medieval. En su concepción filosófico-antropológica del ser humano, tal como explica en su Guía de los perplejos (2:36-38), los sueños carecen de toda consideración sobrenatural y son meramente imaginativos.

Un contemporáneo de Almosnino, Salomón Almolí, sefardí como él y residente en Salónica durante sus primeros años de vida, escribió en hebreo acerca de los sueños en su monográfica obra Mefašer helmín, que se publicó por primera vez en Salónica en $1515^{25}$, y que se reeditó varias veces con el nombre de Pitrón halomot ('Interpretación de sueños') ${ }^{26}$. Esta es la obra más cercana a la de nuestro autor, tanto por su proximidad en el tiempo como por su tentativa común de explicar filosóficamente los sueños y su interpretación.

En 1564, Almosnino, ejerciendo a la par de rabino y de filósofo, haciéndose eco de la tradición tanto judía ${ }^{27}$ como no judía ${ }^{28}$, publica el Tratado de los sueños a petición de Yosef Nasí, como indica al inicio del Prólogo ${ }^{29}$ :

[...] me acordo al pressente averme dicho un xabat estando en Bel Veder, que desseaba en grande manera oír cossa buena en el casso de los sueños, ansí en la essencia dellos como en sus cavsas y ser satisfecho de tres dubdas que acerca dellos sienpre tubo; la primera, saber cómo se avía de entender lo que algunos sabios dizen que según son las conplissiones de los ombres assí son sus sueños diferentes [...], cómo haze sus formas diferentes según la diferencia de la tal conposición material; la segunda y que más desseaba

${ }^{25}$ Cf. Y. VINOGRAD, Thesaurus of the Hebrew Book, Salónica 7.

26 Y. Elman publicó una traducción inglesa (Dream Interpretation: From Classical Jewish sources by Rabbi Shelomo Almoli [Hoboken, NJ 1998]) que no aporta datos novedosos.

${ }^{27}$ Maimónides (139v, 151r, 151v, 152r, 156v, 157r) y Raší (141v), la Biblia y el Talmud.

28 En la obra alude frecuentemente a Alberto Magno (139v), Algazalí (139v, 149r), Aristóteles (139v, 141v), Avicena (142v, 149r) y Ptolomeo (140r, 147v).

29 En todas las citas a esta obra me refiero a la edición aljamiada de 1564. Según C. Roth, Duke of Naxos, pág. 170, esta petición la formuló en el año 1559. Describo el sistema de transcripción en el epígrafe 5. 
saber era si avía alguna razón natural que satisfiziesse para bien entender cómo sicnifican las formas que parece conponer la imaginación cosas que an de venir y que sea cierto assí como en el sueño se sicnifica según nuessos sabios quieren; la tercera, qué sea la cavsa que sueña el hombre cosas de mucho tienpo olvidadas, que estando despierto no le vienen a la memoria, y junto con esto, que desseaba en estremo oír bien esponer el testo sobre los sueños que Yossef soltaba y soñava y saber si se podía dar en ellos alguna razón natural allende de ser, como parece, por influencia divina (139v.4-23).

A las tres dudas de Nasí responde Almosnino a lo largo de la obra, después de elaborar una particular teoría de los sueños en un lúcido intento de conjugar las tradicionales teorías de la sabiduría del judaísmo, que conoce a la perfección, con los razonamientos lógicos más avanzados, tomando como modelos a Aristóteles y Maimónides.

No es este el momento de hacer un análisis exhaustivo de la obra ${ }^{30}$, pero sí de recordar que, según Almosnino, los sueños pueden clasificarse en tres grandes grupos: 1) los simples e inciertos; 2) los simples ciertos y verdaderos; y 3) los de inspiración o influencia divina. El sueño que nos ocupa pertenece a la segunda categoría.

La segunda categoría admite sueños de dos especies en razón del soñante: 1) los soñados por los sabios, y 2) los soñados por personas indoctas e iletradas. Premisa básica común a ambos es la certeza de su futuro cumplimiento. Pero para que estos sueños premonitorios lleguen a confirmarse, deben también cumplir otros requisitos: «que no queden las formas de la imaginación cuando eceden del juizio del entendimiento imprimidas en el ánima del que sueña [...] y que sea estando sanos y bien aconplissionados y que no sea el sueño del principio del dormir, luego después de la comida» (145r-v).

Indica también Almosnino las cualidades óptimas de un intérprete para autentificar la significación del sueño: «es menester que sea sabio, prudente y tenga buena estimativa y esperencia» (146r), ya

30 Un breve resumen puede verse en P. ROMEU, «Una teoría de los sueños de Moisés Almosnino», Álef 3 (Barcelona 1992) págs. 26-27. 
que las reglas no son de aplicación sistemática, pues «un mismo sueño en dos ombres diferentes haze diferentes sicnificaciones» (146r aludiendo a TB Ber 55b).

\section{El SUEÑO DE ALMOSNINO}

El sueño de Almosnino, cuyo texto transcribo en caracteres latinos al final de este estudio, ocupa en el Tratado de los sueños desde la hoja $159 \mathrm{v}$ hasta la $162 \mathrm{v}{ }^{31}$. Partiendo de la base de que el sueño es utilizado por el autor como recurso literario, analizaremos su secuencia lógica para ver de qué modo construye la argumentación. En primer lugar describe el sueño, después lo clasifica y, por último, lo compara con los sueños del patriarca José ( $G n 37$ y ss).

\section{Descripción del sueño}

La escena ocurre en el lugar destinado a la oración en la residencia familiar de los Nasí, el palacio Belvedere en Pera ${ }^{32}$. La espléndida pieza acoge una reunión litúrgica con motivo de la fiesta de Sukot. En sus sitiales acostumbrados están sentados Yosef y Samuel Nasí. Asoman en la 'azará doña Gracia, su hija Reina y su sobrina Beatriz ${ }^{33}$. En un lugar preferente, destinado a los sabios, junto a los escritos santos, observa Almosnino. Numerosos invitados están presentes en el acto. Los protagonistas masculinos salmodian agitando el ramillete preceptivo de la fiesta, que contiene los símbolos clave del sueño: el lulav y el etrog. El sueño se repite tras un breve intervalo

${ }^{31}$ M. LAZAR publicó este sueño en caracteres hebraicos y latinos en su obra Sefarad in my Heart. A Ladino Reader (Labyrinthos 1999) págs. 416-423, pero sin explicarlo ni acotar las citas.

${ }^{32}$ Pera es hoy un céntrico barrio de Estambul, pero desde el siglo XVI y hasta tiempos recientes fue un barrio esencialmente sefardí.

${ }^{33}$ C. Roth, Duke of Naxos, págs. 249-250, nota 48, dice que estas señoras son doña Gracia, Reina y la hija de Samuel Nasí. Esta suposición contradice lo que el texto arguye acerca de «los beatíssimos hijos que vuessa merced y el señor don Xemuel ternán» (160r). 
y en él aprehende el soñante el significado a través de sus símbolos: la palma presagia victoria y la cidra predice descendencia.

En tan aparentemente banal escena nada es producto del azar, sino de la formación rabínica del autor. Según el Talmud: «Si uno ve mirto en su sueño, tendrá fortuna [...] si uno ve cidra, será glorificado» (TB Ber 57a). La fortuna significa no sólo prosperidad económica, sino también condición social, y se explica porque el mirto tiene muchas hojas. De ahí la subsiguiente cita en el texto de Salmos 92:13: «El justo florecerá cual palma». La cidra augura la gloria o el honor que uno recibe a través de la propia descendencia. Según la tradición judía, cada una de estas plantas simboliza la deidad (Mid. LvR 30:9). Lo propio ocurre con los libros que se veneran en la ficción y que cumplen la más alta función simbólica: la presencia divina y su alianza con el pueblo judío por medio de la Ley. Ejercitarse en esa Ley es el más noble deber del buen judío.

Importa especialmente a Almosnino destacar los grandes beneficios que la empresa de doña Gracia y sus sobrinos reportó a las comunidades judías orientales, engrosadas de modo creciente a medida que los diversos países occidentales iban decretando el desalojo de los judíos de sus tierras. Muestra palmaria de la munificencia que les caracterizaba la tenemos en el propio texto: «se glorificarán y alegrarán con la prosperidad manifiesta a todo el mundo y enxalçamiento de la ley que ella [doña Gracia] senpre tuvo $y$ tiene por costumbre de hazer», o «tanto cuanto vuessa merced fuesse enxalçado, tanto más enxalçaría la ley» (160r). Almosnino debía de tener presente que a la Señora se dedicó la Biblia de Ferrara, cuya edición respondía a unas necesidades muy precisas ${ }^{34}$.

Además, Almosnino se siente obligado, por su condición de rabino, a agradecer a los Nasí su magnanimidad para con la colectividad, pero también la consideración de la que disfruta a título individual: «por me hazer fabor como senpre hazía» (159v).

${ }^{34}$ Véase M. ORFALI, «Contexto teológico y social de la Biblia de Ferrara», en Introducción a la Biblia de Ferrara: Actas del Simposio Internacional ..., ed. I. M. HASSÁN y A. BERENGUER AMADOR (Madrid 1994) págs. 229 y ss. 
Samuel y Yosef Nasí, y también doña Gracia, se revelan en el sueño como buenos judíos, pues santifican las fiestas, ayudan al sostenimiento de las comunidades y cumplen algunos de los más importantes preceptos de la ley mosaica:

1) El de alegrarse y santificar las fiestas, pues «es miçvá en moed de alegrarse la presona [...] por kabod del Xy' 't [...] miatad en meldar y miatad en comer y beber [...] él y su mujer y sus ijos y los de su casa $[. .$.$] no es comer y beber y enboracharse y salir afuera del$ odren y los aniyim que estén deseosos [...] en moed es alegría de miçvá que trabajemos en la ley» (ML Vayicrá, Emor cap. 8).

2) El de Génesis 1:28: «procread y multiplicaos». "Y sabrex que assegún es obligado el ombre en la miçvá de periyá urbiyá a tener hijos, lo mismo tiene otro obligo de periyá urbiyá de la ley santa, que es obligado de trabajar en la ley para entenderla asta onde le alcança su meollo» (ML Berexit, Berexit cap. 6).

3) El de sostener a los sabios para que se ocupen de la oración y el estudio, pues «todo guebir que lo mantiene al talmid haham recibe berahot de los cielos y de la tiera y es zohé a dos mesas, quere dezir que tiene bien en este mundo y también en el otro mundo, lo cual no es zohé ninguna pressona de ser rico en este mundo y tener cavdal en olam abá. Solamente el quen favorece al talmid haham de modo que pueda estar meldando de contino, que si no fuera por esto era muhrah aquel talmid haham de cerar el libro para ir a buscar de ónde mantener su casa» (ML Berexit, Vaihí cap. 4).

4) El de acoger a los forasteros: «no es sólo por los probes, que aquello se llama çedacá, pero es también a los ricos, que siendo la pressona forastero en civdad ajena y no conoce a ninguno, no tiene quien le haga algún guisado, aunque tiene moneda se llama probe» (ML Berexit, Vayerá cap. 4).

A ellos, pues, no se les puede desear cosa mejor que mayor fortuna y poder y una larga descendencia. Doña Gracia ya tenía descendencia en ese momento y probablemente mayor poder que sus sobrinos varones, aunque fuera sólo por la razón de que ella era mayor en edad. 


\section{Clasificación del sueño}

Almosnino ni siquiera descarta por evidente que este sueño sea del tercer género, el de los de inspiración o influencia divina. Sin embargo, afirma que es del segundo género negando confluir en él alguna de las causas que originan las tres primeras especies del primer género de sueños inciertos. En primer lugar, porque es un hombre sano "sin alteración de ninguna calidad estraña» (160v) y sueña de madrugada, cuando la digestión de los alimentos «que cavsa la esilación de fumos o vapores al celebro» (160v) no puede alterar el sueño; en segundo lugar, por «ser el dicho sueño sobre otra pressona [...] que cuando el mismo soñador sueña [...] puede ser las más de las vezes por andar fantasseando» (160v); y, en tercer lugar, por su calidad intrínseca de sabio, «porque aunque mi ingenio sea muy flaco [...] tengo por cierto nunca aver concebido en mi concebto imaginaciones vanas» (161r).

Si añadimos a estas razones la secuencia lógica: soñé de madrugada, me desperté, me volví a dormir, volví a soñar, interpreté el sueño soñando y me desperté; y la evidencia de ser el sueño acerca de otro, se cumplen todas las premisas del postulado talmúdico de rabí Yohanán, que es la base de la argumentación de Almosnino: «Tres especies de sueños llegan a ser realizados: el sueño del alba, el que un amigo ha tenido sobre ti y el que ha sido interpretado en el mismo sueño; algunos añaden también el sueño que ha sido soñado dos veces» (TB y TY Ber 55b y IX).

La certeza de la explicación queda garantizada porque el sueño fue soñado dos veces, por lo que se descarta la intervención de la imaginación consciente, y porque en el segundo sueño se descifró.

\section{Comparación con los sueños de José}

Almosnino basa la similitud de esta visión con las de José en la certeza de su futuro cumplimiento. La interpretación de los sueños de la historia bíblica fue correcta, como se demostró después. Aun considerando en ellos la influencia divina, el razonamiento de Al- 
mosnino quiere mostrarnos que así como el Dios de Israel encumbró a José para que un príncipe poderoso paliara las dificultades de su pueblo en la diáspora de Egipto, del mismo modo un príncipe poderoso como Yosef Nasí, que ayuda a su pueblo en esta nueva diáspora, será encumbrado ${ }^{35}$.

Pero, además, este sueño de Almosnino tiene con los sueños de José múltiples paralelismos, premeditados o fortuitos. La figura de José tiene un destacado papel dentro de la tradición sefardí. Sin embargo, el asunto principal de las obras literarias creadas en torno al personaje (teatro, coplas, etc.), tiene que ver con los sucesos que acaecieron en la época en que José estaba ya en Egipto y no en Canaán. Como medida previa, Almosnino anuncia que la comparación tiene lugar «allándome al pressente en el tienpo que leemos los sueños que Yossef soñava y soltava» (139r). La historia de José suele leerse en la liturgia judía a mediados del mes de kislev. Suponiendo que el sueño fue publicado inmediatamente después de ser escrito, el mes de kislev del año 5324 de la era judía correspondía a noviembre-diciembre de 1563.

En primer lugar, y como paralelismo más evidente, los protagonistas de ambos sueños se llaman del mismo modo, José, y ambos tienen un hermano querido, Benjamín y Samuel. En segundo lugar, los símbolos vegetales de ambas figuraciones son también coincidentes: gavillas en el primero de los sueños de José, palmas en el de Almosnino. Además, también José soñó dos veces: una relatada en Génesis 37:5-7 y la otra en Génesis 37:9.

En el segundo de los sueños de José, su madre, Raquel, simbolizada por la luna, le adora. Raquel es considerada por la tradición judía una de las madres de Israel, junto a Sara, Rebeca y Lea, pero ya había muerto cuando ocurrieron los sueños de su hijo (Cf. TB Ber 55b). La figura de Raquel sería comparable en el texto a doña Gracia, que actuó como «madre» providente de los más necesitados

35 También otro contemporáneo de Nasí, Eliézer Ašquenazí, en el prólogo de su obra Yosef lécah (Cremona 1576) lo equiparó por su trascendencia en la historia judía con José, pues alcanzó un poder similar entre extranjeros. Cf. C. RoTH, Duke of Naxos, pág. 162. 
de su pueblo. Sin embargo, en la visión de Almosnino ella tiene menor realce del que cabía esperar. Esta notable ausencia ha sido explicada porque presuntamente en esa fecha no estaba ya en Turquía, sino en Israel ${ }^{36}$.

Y, en fin, la premonición en ambas series de sueños es idéntica: a ambos José -y aquí también a Samuel- se les augura poder y amplia descendencia.

\section{CONCLUSIÓN DEL PRESAGIO}

Consideremos, para terminar, en qué medida se cumplieron los vaticinios de Almosnino sobre Samuel y Yosef Nasí.

A fines de 1563 y principios de 1564, cuando Almosnino redactaba el Tratado de los sueños, gobernaba aún Solimán el Magnífico. A este sultán le complacía enormemente la arquitectura, de modo que mandó construir y reconstruir toda clase de suntuosos edificios, acueductos, murallas, mezquitas... Se especula que entre sus ambiciosos proyectos se contaba en esa época el que pretendía hacer de Tiberíades una gran ciudad, pero no se sabe con precisión las funciones que tendría en él la familia Nasí ni su supuesto padrinazgo ${ }^{37}$.

El 13 de septiembre de 1563, a través de una carta del embajador francés a la Corte, se sabe que este proyecto dejaba vía libre para construir una ciudad cerca de Safed donde vivirían únicamente judíos. Doña Gracia vería cumplidos sus sueños de poder establecer en Palestina una patria para ellos.

La única concreción de este proyecto se divulgó tres años más tarde mediante un decreto de Solimán de 13 de mayo de 1566, por el que dejaba el control de Tiberíades en manos de doña Gracia mediante un pago anual y se autorizaban nuevos asentamientos judíos. Existe constancia documental de que en esa zona hubo un intento

36 Cf. C. Roth, Doña Gracia, pág. 207, nota 6.

37 Véase D. KaufMan, «Don Joseph Nassi...», pág. 293, y A. DAVID, «The Nasi family and the reconstruction of Tiberias», en First International Congress on Turkish Jewry (Tel-Aviv 1990). 
efectivo de reconstrucción, y que algunas de las más importantes escuelas que ahí se crearon continuaron su actividad hasta entrado el siglo XVII, aunque tal vez la resonancia de esta iniciativa fuera menor de la que se esperaba.

No ostentaba tampoco Yosef Nasí, cuando Almosnino publicó el Tratado de los sueños en 1564, el título de duque de Naxos que le hizo famoso y que le fue concedido por su amigo Selim, hijo de Solimán, al poco tiempo de subir al trono en 1566.

Otra de sus mayores y firmes ambiciones era ser nombrado rey o, al menos, gobernador de la isla de Chipre. A este empeño dedicó los últimos años de su vida y hubo de frustrarse a la postre cuando, después de la controvertida y costosísima conquista de la isla por los otomanos en 1573, se nombró a un turco para el cargo.

Almosnino debía de conocer estos tres ambiciosos proyectos de boca del propio Yosef Nasí, y probablemente el futuro que preconizaba tenía relación con ellos. Sin embargo, confraternizaba mejor con su hermano Samuel, pues era de natural más pacífico. De otro modo, no se explica que hermano de tan destacado personaje haya dejado tras de sí el más perfecto de los olvidos. Del sueño mismo se desprende que el autor equipara a ambos hermanos, pese a ser mayor la fama de Yosef, pues «veía a vuessa merced assentado en una silla muy rica. Y de la otra parte estaba el señor don Xemuel su ermano en otra [silla también muy rica]» (159v). A Samuel Nasí no se le conoce ningún cargo público importante y no se sabe si dejó descendencia, porque no se menciona en ninguna de las fuentes que he podido consultar.

Así pues, las premoniciones de Almosnino no se cumplieron ${ }^{38} \mathrm{o}$, mejor, se cumplieron sólo en parte. Es verdad que Yosef Nasí llegó a alcanzar un gran poder político en la corte otomana tanto con Solimán como con Selim II, y que no menguó con la llegada al trono de su hijo Murad III a su muerte en 1574. De esta sólida posición debía de algún modo beneficiarse su hermano, aunque no tengamos constancia escrita.

38 Como puso de relieve C. Roth, Duke of Naxos, pág. 172. 
Pero si grande fue su fortuna en vida, se desvaneció rápido tras su muerte en 1579. Del matrimonio de don Yosef con Reina se cree que no hubo hijos ${ }^{39}$. Su hermano Samuel había muerto diez años antes en 1569, como doña Gracia, y de su hipotética descendencia se desconoce absolutamente todo. A su muerte, sus bienes fueron confiscados por el Estado para cubrir presuntas deudas. Se dice que la duquesa de Naxos sólo recibió de la inmensa fortuna unos noventa mil ducados, que le permitieron vivir muy modestamente, o, por lo menos, más modestamente de lo que en rigor le hubiera correspondido, hasta su muerte en 1599. Sin embargo, tuvo tiempo para instalar en su palacio de Belvedere una imprenta que regentaba a su costa Yosef Ascaloni, instituyéndose así en la primera mujer judía impresora de la Historia.

La doble vertiente premonitoria del sueño, pese a los encomiables anhelos de Almosnino, fue realmente un sueño - $i$ simple e incierto?-, pues su fama no les sobrevivió ni llegaron a tener descendencia. Si acaso tuvieron hijos, su proyección en la vida social, política y económica de la época es, desde luego, ignota. En compensación, nos queda este singular testimonio de una de las épocas más gratificantes de la historia judía: la del renacer del pueblo sefardí en la diáspora.

$\mathrm{Si}$, en cambio, lo que se proponía Almosnino era justamente legar a la posteridad el testimonio de esa época y de los personajes claves que aseguraron la continuidad del pueblo de Israel en la diáspora recién formada a partir de 1492 -como fue clave José desde Egipto en época de carestía-, lo consiguió. Hoy resulta impensable abordar el judaísmo sefardí del siglo XVI sin traer a colación algún miembro de la familia Méndez-Nasí.

39 J. REZNIK, Le duc Joseph de Naxos, pág. 223, nota 17, citando a S. Rosanes, dice que tuvieron una hija. 


\section{CRITERIOS DE EDICIÓN}

Empleo el sistema de transcripción propuesto por Elena Romero en la «Epístola a un levantino sobre los usos occidentales» ${ }^{40}(\mathrm{Ju}$ daísmo hispano: Estudios en memoria de José Luis Lacave Riaño, Madrid 2002), basado en la antigua grafía hispánica, según la cual translitero la aljamía hebraica, reflejando sin corregir grafías anómalas como cassa o juçgaba, aljamiadas ambas con sin.

Sin embargo, dado que el Tratado de los sueños de Almosnino se anticipa en dos siglos a La güerta de oro de David Atías (Liorna 1778) que Romero estudia, me ha parecido ineludible reflejar además con hache la hé hebrea inicial de ciertas palabras castellanas que en los siglos XV y XVI tenían presumiblemente una cierta aspiración, como señaló Menéndez Pidal ${ }^{41}$. Esta hé desapareció de los textos aljamiados en el siglo XVIII, y en castellano es hoy muda. Además, en el Tratado, como en los demás textos aljamiados de ese siglo, una misma palabra admite variantes (onor/honor).

En nota indico los errores tipográficos del texto. Entre corchetes desarrollo las abreviaturas, suplo las omisiones tipográficas e indico las fuentes. Las anotaciones marginales están redactadas en hebreo, pero se traducen en nota, lo mismo que las abreviaturas que contienen. Las hojas del original se indican mediante el número, seguido de «r/v», volados. La línea volada marca dónde se parten las líneas $5,10,15,20,25,30$ y 35 .

Para no entorpecer la buena marcha de la lectura, sólo recojo en notas la explicaciones léxicas que me han parecido imprescindibles. Para eventuales precisiones remito a los diccionarios castellanos y sefardíes al uso ${ }^{42}$.

40 Que resulta semejante al que con algunos cambios utilicé yo misma en Los dos mellizos (Novela en lengua sefardí) (Barcelona 2001).

41 R. MENÉndez PIDAl, Manual de gramática histórica española $\left(23^{\mathrm{a}}\right.$ ed. Madrid 1999) pág. 114.

42 J. COROMInAS y J. A. PASCUAL, Diccionario crítico etimológico castellano e hispánico (Madrid 1987); J. NEHAMA, Dictionnaire du Judéo-espagnol (Madrid 1977); y D. M. BUNIS, A Lexicon of the Hebrew and Aramaic Elements in Modern Judezmo (Jerusalén 1993). 


\section{El SUEÑO DE MOISÉS ALMOSNINO}

${ }^{159} \mathrm{v} / H e c h o{ }^{43}$ todo el discurso passado de los sueños ciertos y inciertos como es dicho, diré a vuessa merced el sueño que soñaba, el cual me mobió principalmente a toda esta especulación passada.

Y certifico a vuessa merced que acabando que ube de soñar me esperté, y ${ }^{15}$ aun que era hazia la mañana, viendo que aún no era de día, me torné a dormir; y súpito fui traspuesto en el propio sueño y por postre me parecía soñar que era sueño y que yo propio lo soltaba ${ }^{44}$, el cual es éste:

Parecíame estar en el midrax ${ }^{45}$ que vuessa merced fragó en Bel Veder, estando el dicho midrax muy suntuosamente ${ }^{110}$ paramentado de muy riquíssima tapicería, assí las paredes dél como todos los assientos al deredor. Y veía a vuessa merced assentado en una silla muy rica ${ }^{46}$; y de la otra parte estaba el señor don Xemuel su ermano en otra.

Y parecíame ser día de grandíssima fiesta y alegría común y que para celebrar ${ }^{115}$ más la fiesta se sacaban los sefarim ${ }^{47}$ del ehal ${ }^{48} \mathrm{y}$ se ponían de manera que venía a estar vuessa merced junto pegado con ellos a la parte derecha y el señor don Xemuel a la otra.

43 En el margen derecho, entre las líneas 1-7: «Explicación del sueño que 'soñé acerca del señor 'felicísimo don Yosef 'Nasí, que en el amanecer 'nació y fue interpretado en el mismo'sueño, y se repitió el sueño 'dos veces».

${ }^{44}$ Soltar 'interpretar'.

45 Mediante midrax o bet midrax (lit. 'casa de estudio') se refiere a la cámara del palacio que servía de lugar de culto.

${ }^{46}$ En el margen derecho, entre las líneas 12-23: «El sueño fue que vi 'al señor mencionado sentado 'sobre una silla alta y elevada 'junto al ehal, a la derecha 'de los libros, y a su hermano 'menor a su izquierda; 'y tenían un lulav y un etrog 'bonitísimos en la mano cada uno'de ellos; y todo el pueblo 'estaba entre ellos, 'en su bet midrax, 'alegres y de buen humor». El ehal es el armario adosado a la pared oriental de la sinagoga donde se guardan los rollos sagrados. El lulav es un ramillete formado por una rama de palma, tres de mirto y dos de sauce ( $L v 23: 40)$ y el etrog es la cidra, fruto del cidro, semejante al limón.

47 'Libros', pero aludiendo a los rollos sagrados en los que está escrito el Fentateuco, para uso litúrgico.

48 Véase nota 46. 
Y me parecía que las puertas de red ${ }^{49}$ de anbas las partes eran abiertas de par en par, onde estaban la beatíssima señora y señoras su hija y sobrina sentadas.

$\mathrm{Y}^{120}$ la resta de la gente de cassa, con muchos otros de fuera muy calificados, en deredor muy bien acomodados. Y todos los haha$\mathrm{mim}^{50}$ estaban assentados en un banco muy elevado que vuessa merced mandaba poner debaxo del assiento de los sefarim entre su silla y la del señor don Xemuel, entre los cuales por me hazer fabor como senpre hazía me mandaba assentar.

$\mathrm{Y}$ assentado ${ }^{125}$ que era alçaba los ojos para vuessas mercedes alegrándome con su próspero estado; y veíales tener a cada uno en la mano diestra una palma muy verde y muy derecha, y en la siniestra una cidra muy fresca y muy linpia como se requieren para hazer con ellos la miçvá que el Dio nos mandó hazer según nuessos sabios escribieron ${ }^{51}$.

Y estando assí ${ }^{130}$ en esta visión tan elevado, me parecía que vuessa merced mobía dicha palma junto con la cidra a todas partes diziendo a alta boz: Dirá agora Yisrael que para senpre su merced ${ }^{52}$ [Sal 118:2], y respondíamos todos cuantos allí nos hallábamos y dezíamos: Load a Adonay que bueno, que para senpre su merced ${ }^{53}$ [Sal 118:1].

$\mathrm{Y}$ estando con estas palabras en la boca me ${ }^{135}$ desperté. Y queriéndome alevantar para bien contenplar en el sueño, pareciéndome aún algo tenprano, me torné súpito a dormir.

49 Se refiere a la celosía de la 'azará u oratorio para las mujeres en la sinagoga.

50 Con la palabra hahamim (lit. 'sabios') se refiere a las personas con alguna competencia en materia religiosa tocante al judaísmo, estudiantes o rabinos, como el propio Almosnino.

${ }^{51}$ Se refiere a la miçvá ('precepto') del lulav (véase nota 46) u obligación de hacerse con uno para participar convenientemente en la fiesta de Sukot o de los Tabernáculos, agitándolo según una norma preestablecida. Esta obligación pesa sobre todo varón judío que pueda tenerlo en la mano, niños incluidos (véase Mišná, Suká 3 y 4).

${ }_{53}$ En el margen derecho, a la altura de la línea 32: «Dirá agora Yisrael».

53 En el margen derecho, a la altura de la línea 33: «Load a Adonay que bueno». 
Y de inprobiso me pareció trasponerme en el mismo lugar en la misma visión, donde sentía tornar a dezir vuessa merced: Dirán agora temientes de Adonay que para sienpre su merced ${ }^{54}$ [Sal 118:4], y todos respondíamos al mismo modo que antes avíamos respondido. ${ }^{160 r /}$ Lo cual juçgaba yo en el mismo sueño que todo aquello que avía visto era soñando y que era sueño de mucha sustancia.

Y soñaba en el mismo sueño que la soltura del sueño era que la palma ${ }^{55}$ sicnificaba una recta y próspera vitoria como todos los ${ }^{15}$ antigos escribieron, muy conforme a lo que nuessos sabios dizen acerca de la razón de tomar la palma en el tienpo que más apropiado quijo el Dio que fuesse para celebrar nuestra fiesta y alegrarnos delante dél.

Y tenerla vuessa merced en la mano muy verde y muy recta, meneándola a todas las partes del mundo, era verdadera demostración de ser su ${ }^{110}$ vitoria recta y florida, ordenada por la probidencia divina, de tal manera que tracendiesse su fama y fuesse bien notoria en todas las partes del mundo en continuo aumento de prosperidad, de modo que en él se afirmasse el dicho de nuesso diviníssimo rey salmista, do dixo: Justo como la palma florecerá e cét[era] ${ }^{56}$ [Sal 92:13].

Y la cidra, que es fruto tan suavíssimo en sabor ${ }^{115}$ y olor, más que otro alguno como nuessos sabios quieren, era sicnificación a los beatíssimos hijos que vuessa merced y el señor don Xemuel ternán, perfectíssimos en especulación que sicnifica el olor, y bien obrar que sicnifica el sabor, que es la propia conparación que nuessos sabios hizieron [Cf. Mid. $L v R$ 30:12]. Y todos juntos, padres y hijos que dellos ${ }^{120}$ salrán, será la fama de sus obras y divina especulación espandida junto con su vitoria por todas las partes del mundo.

${ }^{54}$ En el margen derecho, a la altura de la línea 38: «Dirán agora temientes de Adonay».

55 En el margen izquierdo, entre las líneas 3-7: «Esta es la soltura que se soltó 'del propio sueño: 'el lulav muestra 'la victoria y el etrog 'muestra acerca de los hijos».

56 En el margen izquierdo, a la altura de la línea 13: «Justo como la palma florecerá». 
Y estar vuessas mercedes junto con los sefarim era sicnificación que serán todas sus obras, con todas sus prosperidades, conformes a nuessa sacra ley. Y por sus cavsas y intrecessión será dicha ley ${ }^{125}$ sublimada y enxalçada en público y no amagada, por lo cual estaban los sefarim defuera y en alto, más que el andar ${ }^{57}$ del assiento de vuessa merced, sicnificando que tanto cuanto vuessa merced fuese enxalçado, tanto más enxalçaría la ley, juçgando la cavsa por el efecto conforme a el dicho de nuesso sapientíssimo rey Xelomó en sus proberbios, do dize: ${ }^{130}$ Enxálçala y enaltecerteá e cét[era] ${ }^{58}[\mathrm{Pr}$ $4: 8]$.

Y tener nuessa beatíssima señora y la señora su hija y sobrina, que el Dio guarde, las puertas abiertas mirando todo lo dicho, era sicnificación que se glorificarán y alegrarán con la prosperidad manifiesta a todo el mundo y enxalçamiento de la ley que ella senpre tubo ${ }^{135} \mathrm{y}$ tiene por costumbre de hazer, que tan purificada y sacra intención el Dio nunca manca de poner en efecto, como nuessos sabios dizen que la intención buena el Dio la trae a efecto e cét[era] ${ }^{59}$ [Cfr. TB Kid 39b-40a], conforme a lo que nuesso divino rey David dixo: Voluntad de sus temientes fará e cét[era] ${ }^{60}$ [Sal 145:19].

Y por que de su favor y prosperidad y de los que de ellos sucederán se resultará bien a todo Yisrael, dezía vuessa merced: Dirá agora Yisrael que para sienpre su merced e cét[era]; lo cual, por que será de todos ${ }^{160 v /}$ concedido, juntamente y a altas bozes respondíamos y dezíamos con justa razón loar todos al Dio, y dezir su merced ser infinita en darnos tan buen medio para nuestro bien.

$\mathrm{Y}$ el assiento que vuesa merced mandaba meter para los hahamim debaxo del assiento de los sefarim, entre ${ }^{15}$ él y el señor don Xemuel,

57 'Estrado'; cf. port. andar.

58 En el margen izquierdo, a la altura de la línea 30: «Enxálçala y enaltecerteá».

59 En el margen izquierdo, entre las líneas 37-39: «La intención buena 'la combina el Santo, bendito Él, 'con [la buena] obra».

60 En el margen izquierdo, entre las líneas 40-41: «Voluntad de sus temientes fará'y su clamor escuchará». 
era sicnificación que los sabios que de contino tienen la ley sobre sus cabeças, trabajando en ella como deven, serán sublimados y abraçados de todas las partes del fabor y onor y próspero estado de vuessas mercedes para que por sus manos se afirme el dicho de nuesso profeta Yexayau, do dixo: $H^{\prime}$ ['Adonay'] envoluntán por su justedad que se ${ }^{110}$ engrandeça la ley e cét[era] ${ }^{61}$ [Is 42:21].

Por lo cual, tornando a dormir, trasponiéndome en la misma visión, oía dezir segunda veç a vuessa merced ${ }^{62}$ : Dirán agora temientes de $H^{\prime}$ que para senpre su merced e cét[era], que era sicnificar ser particularmente manifiesta y conocida la misericordia divina en todo este bien a los temientes a el Dio, ${ }^{115}$ allende del conocimiento que la unibersalidad de Yisrael ternán, el cual sicnificó el primero dicho.

Espero en nuesso clementíssimo Señor que assí será, como lo soltaba, y que todos los d[i]chos que tan alegremente deseamos se afirmarán; por que allende de ser la razón evidente de no poder mancar de ser assí ordenado por la probidencia ${ }^{120}$ divina, abiendo tanto merecimiento y razón para ello, tengo esperança por la sicnificación deste mi sueño que assí sea, por sus cavsas naturales o filossofales, conforme a cuanto tenemos dicho ${ }^{63}$, aviendo bien atentado y visto que no mancaron en él ninguna de las circunstancias que nuessos sabios porsuponen que se requieren para ser ${ }^{125}$ su sicnificación verdadera conforme a razón natural.

Lo primero estar yo al pressente, bendito el Dio, sano, sin alteración de ninguna calidad estraña, y ser el sueño hazia la mañana, que dizen nuessos sabios que siendo assí no manca el efecto y es por ser depués de acabada la última digestión de la comida ${ }^{64}$, que cavsa la

${ }^{61}$ En el margen derecho, entre las líneas 9-10: «Adonay envoluntán por'su justedad que se engrandezca la ley».

${ }^{62}$ En el margen derecho, a la altura de la línea 12: «Dirán agora temientes de Adonay».

${ }^{63}$ En el margen derecho, entre las líneas 22-27: «Comentario de las justas causas, 'según razón natural 'recta, de que sea 'el sueño mencionado justo 'y verídico en todas las particularidades'de solución mencionadas».

${ }^{64}$ En el margen derecho, entre las líneas 29-34: «La primera razón que no sea 'del primer género 'de sueños inciertos, 'por la creación 'de humos o vapores 'que suben al meollo». 
${ }^{130}$ esilación de fumos o vapores al celebro; lo cual es todo demostración de no aver ninguna cavsa de las que tenemos dicho acerca de la primera especia del primer género antepuesto, que cavsan ser los sueños inciertos.

Lo segundo ser el dicho sueño sobre otra pressona fuera del que sueña, que dizen nuessos sabios que el sueño ${ }^{135}$ que sueña uno en cassos de otros es el que más cierto se afirma e cét[era]. Y la intención desto pienso que sea por salvar la segunda especia del primer género de sueños inciertos, y la cavsa será que cuando el mismo soñador sueña cassos que sicnifican algún efecto en él mismo ${ }^{65}$, puede ser las más de las vezes por andar fantaseando en ello, que desseándolo mucho y pensando reziamente en él, ${ }^{161 r}$ es cavza de trespassarse en la imaginación al tienpo del dormir, como diximos; lo c[u]al, siendo que otro afuera de él lo sueña, aun que mucho lo desee en estremo, juçga más desapassionadamente la razón del efecto. Por lo cual es bien visto no ser este mi sueño de la segunda especia del primer ${ }^{15}$ género antepuesto.

Pues no ser de la tercera especia no dubdo ${ }^{66}$, porque aun que mi ingenio sea muy flaco y eclicpsado, a lo menos por la prática y esperencia tengo por cierto nunca aver concebido en mi concebto imaginaciones vanas ni variables que no llebassen alguna razón natural. Lo cual tengo por fortíssima cavsa ${ }^{1 / 0}$ para no ser mi sueño de ninguna especia del género primero en ninguna manera. Mas antes siento muchas razones evidentes y señales verdaderas ${ }^{67}$ ser dicha soltura verdadera ${ }^{68}$.

La primera ser el sueño soñado dos vezes, que es grandíssima demostración de ser verdadero y que será presto el efecto con el ayuda [sic] del Dio.

\footnotetext{
65 En el margen derecho, entre las líneas 38-40: «Dijo rabí Yohanán: Todo sueño 'que se sueña por la mañana, 'ocurre inmediatamente. Berešit Rábá».

${ }^{66}$ En el margen izquierdo, entre las líneas 5-9: «Causa de que no sea'tampoco del tipo $3^{\circ}$ 'de los inciertos '[que es] debilidad de espíritu 'y mente del soñante etc.».

${ }^{67}$ Dice verdareras

68 En el margen izquierdo, entre las líneas 11-15: «Explicación de las causas'de que sea'el sueño mencionado del género'segundo de los sueños'verdaderos».
} 
$\mathrm{Y}^{115}$ la razón en esto está vista que es demostración de no ser figura inventada de la imaginación solamente, sin aver en ello juizio prudencial por parte del entendimiento ${ }^{69}$, que si assí fuera nunca conformaran en las dos vezes las unas con las otras, mas fueran muy disformes como es sólito de azer la imaginación contino figuras diferentes pues no son regladas ni ${ }^{120}$ ordenadas según derecha razón, por lo cual conpone unas con otras ${ }^{70}$ las más de las vezes, no siendo refrenada de la razón por parte del entendimiento.

$\mathrm{Y}$ esto quijo sentir Yossef en la sicnificación tan verdadera que soltó en el sueño de Paró, en dezir: $Y$ sobre ser assegundado el sueño a Paró dos vezes, qué aparejada la cossa de con el Dio, y ${ }^{125}$ apressuranse el Dio para fazerla e cét[era] ${ }^{71}$ [Gn 41:32]; que está bien vista la intención que por ser el sueño assegundado como cuenta la Escritura que fue, es demostración de ser el juizio divino verdadero y ser el efecto presto.

La segunda es la que nuessos sabios mucho afirman do quieren ${ }^{72}$ y dizen que el sueño que se suelta en el mismo sueño, aquella soltura es la ${ }^{130} q u$ verdaderamente y sin falta se afirma e cét[era] [TB Ber 55b].

Y tubieron en esto grandíssimo fundamiento de razón natural, por que siendo verdad lo que el filóssofo dixo en el libro De sueño y vigilia que cuando el ombre sueña que sueña el soñar que sueña no puede ser sueño cavsado por la imaginación ${ }^{73}$ como es lo que lla

${ }^{69}$ En el margen izquierdo, entre las líneas 17-20: «La primera causa 'es la repetición del sueño, 'y explicación de la verdadera razón 'al respecto según la naturaleza».

70 Dice otars.

71 En el margen izquierdo, entre las líneas 22-23: «Y sobre ser assegundado el sueño'a Paró dos vezes».

72 En el margen izquierdo, entre las líneas 28-35: «Explicación de la segunda causa' [que es] que el sueño 'fuera soltado 'en el mismo sueño, y explicación 'de la verdadera razón, 'según la naturaleza y la ciencia, 'conforme los dichos de nuestros sabios, de bendita memoria, 'al respecto».

73 La cita es del segundo de los tres tratados sobre el sueño de Aristóteles incluidos en los Parva naturalia, Acerca de los ensueños, y no del primero, Acerca del sueño y la vigilia, como parece indicar, a no ser que se refiera a él genérica- 
mamos sueño, como avemos dicho, salvo ${ }^{135}$ verdadera determinación y sentencia del entendimiento que determina que es obra de la imaginación; por que la misma imaginación nunca puede ella imaginar que imagina, como acaece muchas vezes estando despiertos puestos en alguna rezia imaginación que depués determinamos con derecha razón del entendimientos [sic] contenplando en lo passado ser imaginación, que ${ }^{161 v / a}$ de ser fuera de la misma imaginación.

$Y$ esto es sabido y aberiguado y podría ser que fuese ésta la intención en los sueños de Yossef, que dize: $Y$ soñó Yossef sueño ${ }^{74}$ [Gn 37:5], que es como que dixesse soñó que soñaba, y por esto se afirmaba en ser verdadero.

$\mathrm{Y}$ por la misma cavsa sentenció ser ${ }^{15}$ verdaderos los sueños del escanciano y el panadero porque dixeron: Y soñamos sueño ${ }^{75}[\mathrm{Gn}$ 41:11], siendo ésta la intención que es como que dixessen soñamos que soñávamos e cét[era].

Por todas estas razones está bien visto ser la sicnificación de este mi sueño verdadera. $Y$ si es de la primera especia del segundo género, ${ }^{110}$ determinado el efecto por especulación, o de la segunda considrando por esperencia, no me afirmo ser más por una que por otra, que podría ser aver las dos juntamente, y que sea por una o por otra que cavsan la sicnificación ser verdadera en lo futuro, como avemos dicho.

En este mi sueño me determinó ser símil a los ${ }^{115}$ sueños que Yossef soñaba y contaba a sus hermanos ${ }^{76}$, de los cuales, aun que ellos se burlaban, no mancó el efecto sicnificado sin falta.

Por lo cual Yaacov su padre y nuesso santo patriarca, sintiendo la razón y fundamiento que los tales sueños mostraban tener según ra-

mente como el primero de la serie. Cf. Aristóteles, Acerca de la generación y la corrupción y Tratados breves de historia natural. Introducciones, traducciones y notas de E. LA CROCE y A. BERNABÉ PAJARES (Madrid 1987) pág. 292.

${ }^{74}$ En el margen derecho, a la altura de la línea 3: «Y soñó Yossef sueño».

75 En el margen derecho, a la altura de la línea 6: «Y soñamos sueño», etc.

76 En el margen derecho, entre las líneas 14-20: «Explicación cierta de 'que este sueño se asemeja 'al sueño de José, 'que soñó en la soltura 'que es conforme a naturaleza la causa 'de ser los sueños de José 'verdaderos». 
zón natural, guardó la cossa en su coraçón oído que ubo el sueño, esperando ${ }^{120}$ el efecto sicnificado en él, por lo cual dize la Escritura: $Y$ enbidiaron en él sus ermanos y su padre esperó la cossa ${ }^{77}[\mathrm{Gn}$ 37:11] o guardó la cosa, que el bierbo es equíboco ${ }^{78}$, que puede sufrir los dos intentos y todos son conformes a la intención, que viendo Yaacov ser el sueño tan reglado y aver para efectuarse lo que en él se sicnificaba tantas razones como diremos, guardó ${ }^{125}$ la cossa entre sí porque sus ermanos no lo sintiessen y fuesse cavsa de aborecerlo más; por lo cual cuenta la Escritura que estultó en él ${ }^{79}$ [ $G n$ 37:10] y le bigiló dicho sueño y no dexó ${ }^{80}$ por esso de esperar dicho efecto.

Y la razón natural que siento aver en dichos sueños, no negando que pudiese ser por influencia divina, que es lo último que vuessa ${ }^{130}$ merced mostró dessear de saber, pienso que sea que siendo Yossef él más sabio que todos sus ermanos, según quieren nuessos sabios, que en llamarlo la Escritura hijo de vejezes ${ }^{81}$ [Gn 37:3] quiere dezir hijo sabio.

Lo cual tubieron lugar a mi ver a esta glossa por ver que Binyamín era más pequeño que él y la regla común es llamar al más pequeño hijo de bejeç, pues se hizo en tienpo de más vejeç ${ }^{135}$ que el de antes dél, por tanto dixeron que quiere dezir hijo sabio porque la cencia se halla en los viejos ${ }^{82}$, como dixo nueso rey sapientíssimo en sus proberbios: En los viejos cencia e cét[era] ${ }^{83}$ [ $\mathrm{Jb}$ 12:12].

\footnotetext{
77 En el margen derecho, a la altura de la línea 25: «Y enbidiaron en él sus ermanos».

78 Se refiere al verbo $x . m . r$, que significa 'guardar' y 'esperar'.

79 'Le reprendió'.

80 Dice dexé.

81 En el margen derecho, a la altura de la línea 31: «Porque él hijo de vejezes».

82 En el margen derecho, entre las líneas 32-33: «Según la interpretación de Raxí, 'hijo sabio de Adonay». Explicación proveniente de que el Targum Onquelos traduce zaquén 'anciano' por haham 'sabio'. Véase también TB Kid 32b: «Rabí José el Galileo dijo: Zaquén hace referencia a uno que ha adquirido sabiduría».

83 En el margen derecho, a la altura de la línea 37: «En los viejos 'cencia» etc., cita que no es del libro de los Proverbios de Salomón, como parece anunciar, sino del de $J o b$.
} 
Y dizen más nuessos sabios sobre este mismo dicho que cuanto avía deprendido Yaacov de Xem y de Éber abisó a Yossef e cét[era] ${ }^{84}$ [Mid. GnR 84:8]. Y siendo assí, junto con ser él el más familiar en la casa de su padre y que sabía bien todas sus particularidades, más que ${ }^{162 r /}$ otro cualquiera dellos, tenía bien conocido el sumo grado de ecelencia y supremo merecimiento de su padre, por el cual conocimiento, junto con su saber y prudencia, le cavsaba entender y determinar según derecha razón y recto juizio, que no podía mancar de ser probeído por la probidencia divina ${ }^{85},{ }^{15} \mathrm{de}$ tal manera que él y todos sus sucessores fuessen en un muy próspero estado de todos los bienes en súpera bundancia, assí tenporales como bienes verdaderos del ánima.

Y contenplando y juçgando según derecha razón que el mejor medio y más convenible que el Dio podía aparejar para traer símil efecto era él, por las razones dichas, se determinaba ${ }^{110}$ aver de ser por su intrecessión.

$\mathrm{Y}$ andando contenplando y pesquiriendo el medio que para tal efecto la probidencia divina ordenaría más allegado a razón natural que fuesse possible, como es sólito de hazerse, considrando despierto algunos medios en unibersal, pienso que lo primero que se determinó fue que esto avía de ser hecho por mano de algún príncipe poderoso, que de él ${ }^{15}$ fuessen muy faboridos y que cuando a sus sucesores fuesse contrario pudiesse más mostrar la probidencia divina su poder infinito o símil cossa que ésta, que espierto, con su continua especulación perfectíssimamente caería en la verdad.

Y si algo mancasse en la particularidad dello, atemaría de alcançar durmiendo, por estar el ${ }^{120}$ ánima estonces más dessocupada y auta para alcançar y determinar más la verdad, según declaramos en la primera cavsa de los sueños ser ciertos del segundo género, las cuales determinaciones la imaginación trasponía en figuras sicnificantes el efecto que su entendimiento determinaba.

\footnotetext{
84 En el margen derecho, entre las líneas 39-40: «Cuanto avía deprendido Yaacov'abisó a Yossef».

85 En el margen izquierdo, entre las líneas 4-8: «Explicación 'de la hipótesis más ajustada 'por la que José supuso'que había de proveerse'su sueño».
} 
Lo cual parece por el efecto que juçgado y determinando por ${ }^{125}$ Yossef que de razón avía de ser esto por su intrecessión y que devía de ser por mano de algún príncipe poderoso, como avemos dicho, y que no podía ser salir su padre de aquel lugar si no fuesse con mucha necessidad y siendo la mayor necessidad la hambre, que no se puede en ninguna manera sustentar la vida sin mantenimiento, como es manifiesto, se determinó en el tienpo del dormir ${ }^{130}$ que particularmente avía de ser por cavsa del dicho mantenimiento por su mano, por lo cual la imaginación lo traspuso en que gabillaban gabillas entre el canpo e cét[era] [Gn 37:7]; por lo cual refería que se avían de ir todos a él a encorbar e cét[era] [Gn 37:10]. Lo cual, siendo fundada la tal determinación sobre tan suficientíssimas razones, no mancó el efecto.

${ }^{135}$ Y según la segunda cavsa que allá declaramos ${ }^{86}$, está mucho más vista la razón de ser verdadero, que conligándosse y conjuntándosse con la inteligencia que ponen obrar en nuesso entendimiento, no se debe dubdar que alcançasse la pura verdad del efecto por la certenidad de las cavsas y formas de las cossas que tan verdaderamente se traspassarían en el ánima beatíssima de tan junto ${ }^{87}$ sapientíssimo soñador como él era, como se mostró por el efecto.

${ }^{162 v} /$ Por $^{88}$ la misma cavsa me afirmo en la sicnificación deste mi sueño por todas sus partes ser assí como yo tengo soltado, confiando en el Dio que assí será; porque abiendo yo conocido tan espacificadamente y especulado bien por estenso el sumo grado de ${ }^{15}$ ecelencia de la beatíssima cassa de vuessas mercedes, non podía mi ingenio, por flaco que fuesse, dexar de juçgar que pudiesse por ninguna manera mancar de ser símil cassa sublimada y puesta en la cumbre de felice y próspero estado, ordenado por la probidencia divina.

${ }^{86}$ En el margen izquierdo, entre las líneas 35-40: «Explicación de la causa de que sean 'los sueños de José ciertos 'según la causa segunda 'que mencionamos y es 'la unión 'con el entendimiento agente».

87 Quizás justo.

88 En el margen derecho, entre las líneas 1-4: «Explicación de que sea el sueño 'éste tan cierto como los 'mismos motivos los que 'se mencionaron en el sueño de José». 
Y juçgando esto mi entendimiento según derecha razón, como avemos dicho, ${ }^{110}$ traspassándose el tal juizio en el tienpo del dormir, siendo el ánima más dessocupada para más verdaderamente alcançar la verdad, se determinó y afirmó ser assí y la imaginación la traspuso en la forma que relatado tengo conforme a el juizio verdadero que fue la soltura.

De manera que lo que Yossef alcançó por puro saber y verdadera ${ }^{115}$ especulación, pienso aver yo alcançado a lo menos por esperiencia cierta y derecha razón, que siendo tan manifiestas las cavsas cualquiera juçgará no poder mancar tal efecto; y ser assegundado el sueño y en el tienpo que fue, y ser soltado en el mismo sueño es señal de lo que Yossef dixo: Que es la cossa ordenada y aparejada ${ }^{120}$ y conpuesta de con el Dio y que se apressurará a hazerlo [Gn 41:32]. Y assí sea y Él lo confirme, amén.

A servicio de vuessa merced. Moxé Almosnino.

\section{RESUMEN}

Dos personajes famosos, Moisés Almosnino y Yosef Nasí, coincidieron en un espacio geográfico y temporal común (Salónica-Constantinopla a mediados del siglo XVI). Ambos trabajaron desde allí denodadamente en favor del pueblo sefardí en la diáspora. La realización del sueño premonitorio vendría a colmar las expectativas de ambos.

Palabras Clave: Moisés Almosnino, Josef Nasí, siglo XVI, sueño premonitorio.

\section{SUMMARY}

Moshe Almosnino and Yosef Nasi did not only share a common political and social context, namely Salonica, Constantinople in the $16^{\text {th }}$ century. They also devoted their time and effort to help the Sephardic people of the Diaspora to which they both belonged. One can say that their work got rewarded as the premonitory dream was fulfilled.

KEYWORDS: Moshe Almosnino, Josef Nasi, $16^{\text {th }}$ century, premonitory dream. 


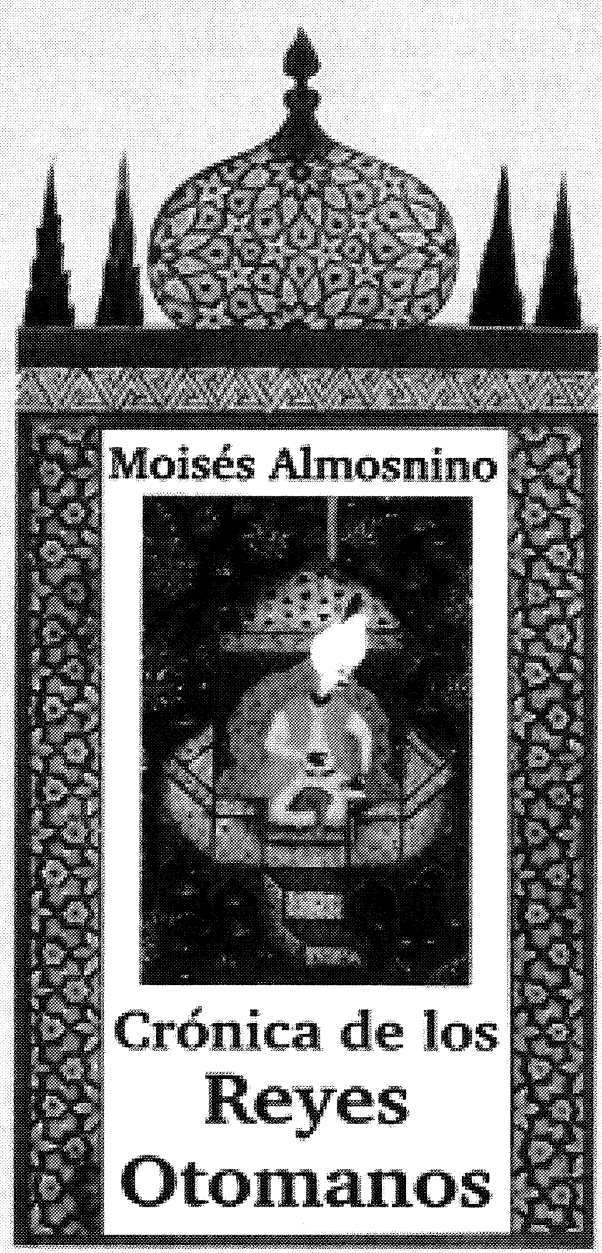

Fig. 1. Moisés Almosnino, Crónica de los Reyes Otomanos (Barcelona 1998). 


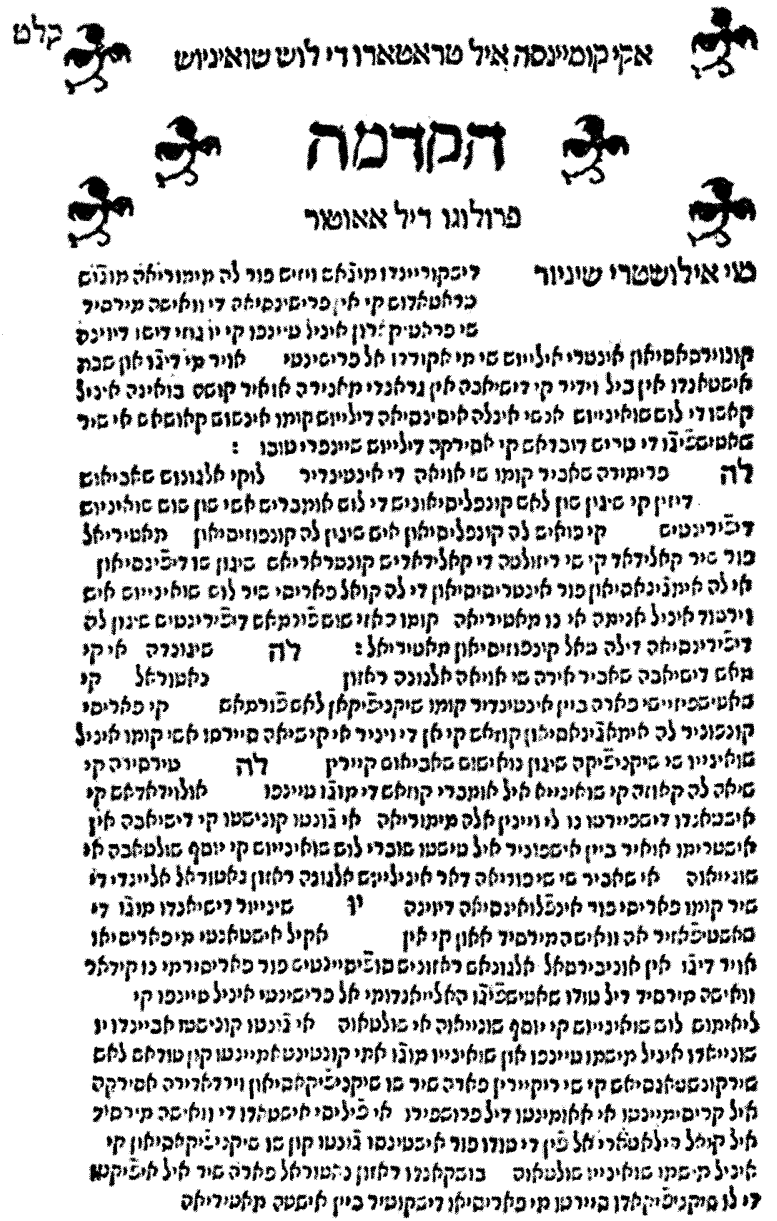

Fig. 2. Hoja 139 del Tratado de los sueños (Salónica 1564). 


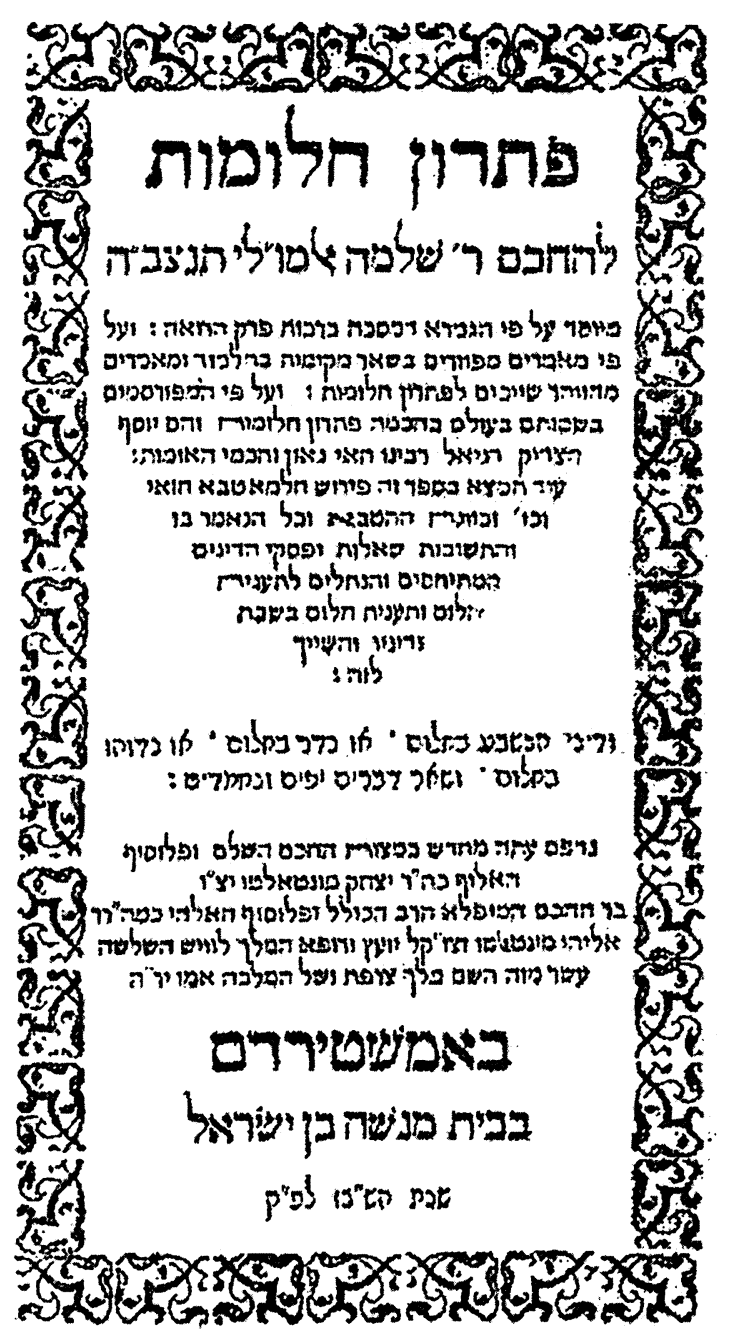

Fig. 3. Salomón Almolí, Pitrón halomot (Amsterdam 1637). 


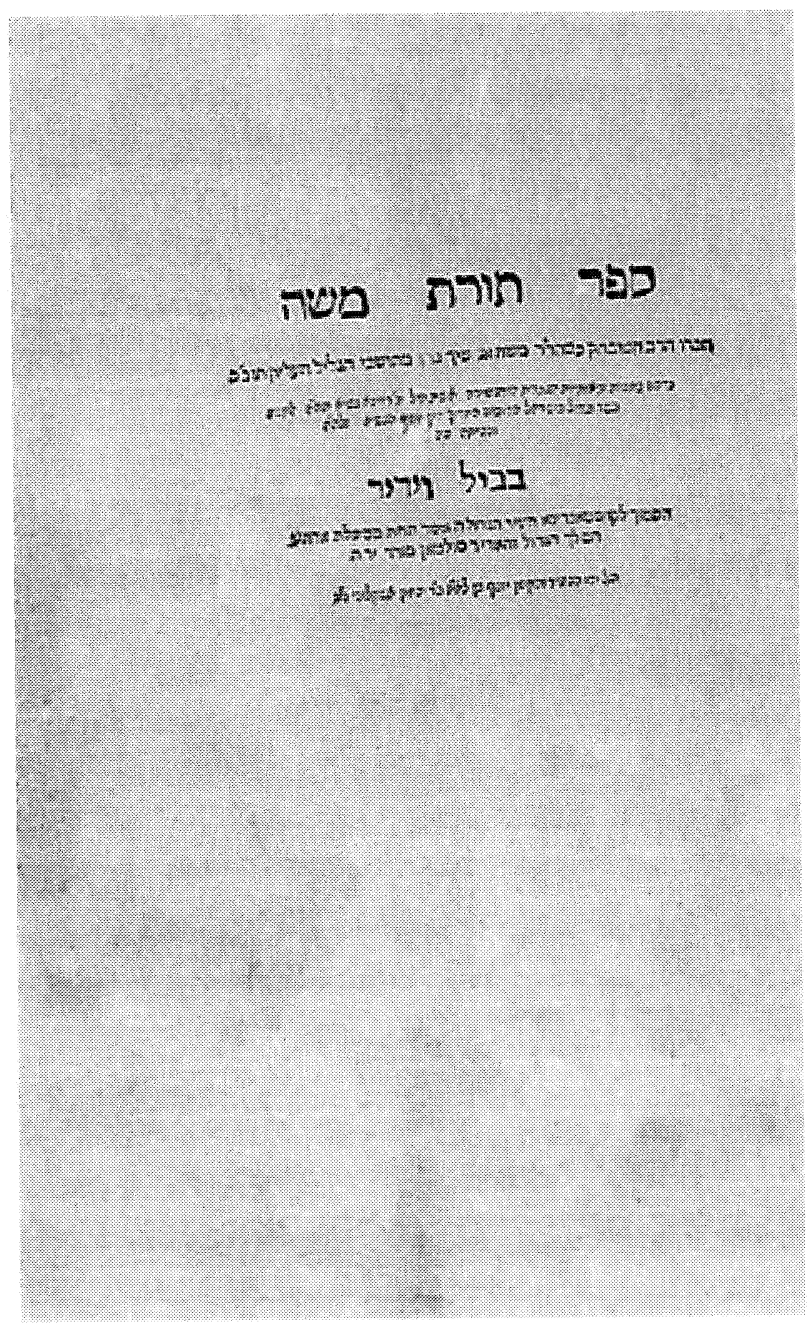

Fig. 4. Mošé Alšej, Séfer Torat Mošé (Belveder 1595). 